\title{
Clinicopathological profile of breast lesions and their management in paediatric patients seen in a tertiary health facility in Southern Nigeria
}

\author{
Okoro Philemon $E^{\star, \dagger, 1}$, Obiorah Christopher ${ }^{2}$ \\ ${ }^{1}$ Departments of Surgery, and Anatomic Pathology, University of Port Harcourt Teaching Hospital, Port Harcourt, Nigeria \\ ${ }^{2}$ Departments of Surgery, and Anatomic Pathology, University of Port Harcourt Teaching Hospital, Port Harcourt, Nigeria \\ DOI: https://doi.org/10.15520/ijmhs.v10i03.2829
}

Accepted 25-02-2020; Received 01-02-2020; Publish Online 12-03-2020

Reviewed By: Dr
Daniel V.
Department:
MEDICAL

The breast is well recognized as a common site of disease in adults, particularly the females. The most feared of the diseases of the breast is cancer of the breast. This is also the reason there is much interest in the breast among researchers and patients alike. [1] On the contrary, diseases

* Corresponding author.

† Email: philemon.okoro@uniport.edu.ng.

\section{ABSTRACT \\ Introduction}

Aims and Objectives

Methods using the SPSS 17.0

\section{Results}

\section{Conclusion}

Breast diseases are less common in the paediatric age group than in adults. Accordingly, less attention has been given to this group of diseases. Hence there is not enough literature on so many aspects including pathology,diagnosis, treatment and outcome. Commonly, surgeons and researchers apply the same principles deployed for adults.

To evaluate the clinical and pathological pattern of paediatric breast diseases seen in our centre, and to review their treatment.

This is a four year retrospective review of cases of breast diseases seen in patients who are of age 18 years and less in our centre from July 2015 to May 2019. The data extracted were age, gender, clinical features, clinical diagnosis, laterality of breast lesion, treatment offered, histological diagnosis. The data were collated and analyzed

One hundred and ninety one cases were analyzed. They comprised 29(15\%) males and $162(85 \%)$ females giving a male female ratio of 1:6. The breast lesions were in the right breast in $84(44 \%)$ cases, in the left breast in $75(39.3 \%)$ cases and bilateral in $32(16.7 \%)$ cases. Breast lumps were the commonest clinical presentation, and fibroadenoma and fibroadenosis constituted $79.2 \%$ of cases. There were no malignant lesions.

Breast lesions are not uncommon among our paediatric patients. The majority of the lesions presented as breast lump in the teenage years. Fibroadenoma and fibroadenosis are the commonest breast lesions and malignant lesions were not encountered. Less invasive methods of diagnosis and treatment are recommended.

Key words: Breast-Lesions-Paediatric-Profile-Management 
often not the case. An understanding of the types of breast lesions seen in our environment among paediatric patients is needed to provide evidence for or against the treatment methods being adopted presently in our practice. Breast malignancies are rare in paediatric patients but they have been reported. [4] Furthermore, reports suggest that progressively younger adult patients are developing breast cancer than was previously the case. [5] Some of these patients though were diagnosed of their breast cancer in adulthood, may have developed symptoms while they were still in their teenage years. A closer look at the clinicopathological pattern of these breast lumps and lesions in our paediatric patients will certainly make way for early diagnosis and better treatment of these patients.

\section{AIMS AND OBJECTIVES}

To evaluate the clinical and pathological pattern of paediatric breast diseases seen in our centre, and to review their treatment.

\section{METHODS}

This is a four year retrospective analytical review of cases of breast diseases seen in patients who are of age 18 years and less in our centre from July 2015 to May 2019. The medical records and pathology reports of these patients were retrieved and scrutinized. Patients who had missing or incomplete records were excluded. The data extracted were age, gender, clinical features, clinical diagnosis, laterality of breast lesion, treatment offered, histological diagnosis. The data were collated and analyzed using the SPSS 17.0

\section{RESULTS}

Two hundred and seventeen patients were diagnosed with breast lesion during the period under review, but 26 were excluded due to incomplete records. One hundred and ninety one cases were therefore analyzed. They comprised 29(15\%) males and $162(85 \%)$ females giving a male female ratio of 1:6. The age range was from 1 month to 18 years with a mean age of $13.1( \pm 2.1)$ years. Table 1 shows the age distribution of patients. The breast lesions were in the right breast in $84(44 \%)$ cases, in the left breast in $75(39.3 \%)$ cases and bilateral in $32(16.7 \%)$ cases. The diagnosis was based on clinical assessment and or imaging only where a biopsy was not considered necessary. The distribution of patients according to the clinical diagnosis is shown in Table 2. The breast lumps were by far the commonest clinical presentation, constituting over (85\%). Biopsy was performed as closed (using core needle) or open as excision or incision in the breast lumps, and the histological diagnosis are shown in Table 3. Fibroadenoma and fibroadenosis (fibrocystic disease) constituted $79.2 \%$ of cases. The distribution of the breast lesions according to the age of the patients is shown in Table 4.
Table 1. Distribution of patients according to age

\begin{tabular}{lll}
\hline Age group & Patients $(\mathrm{n}=191)$ & Percentages \\
$0-3$ & 26 & 13.6 \\
$4-7$ & 11 & 5.8 \\
$8-11$ & 15 & 7.9 \\
$12-15$ & 54 & 28.2 \\
$16-18$ & 85 & 44.5 \\
\hline
\end{tabular}

Table 2. Distribution of patients according to clinical diagnosis of breast lesion

\begin{tabular}{lll}
\hline Clinical Diagnosis & Patients $(\mathrm{n}=191)$ & Percentage \\
Breast lump(neoplastic) & 163 & 85.3 \\
Breast abscess & 8 & 4.2 \\
Puberty mastitis & 7 & 3.7 \\
Mastitis neonatorum & 6 & 3.1 \\
Gynaecomastia & 5 & 2.6 \\
Cavernous haemangioma & 2 & 1.1 \\
\hline
\end{tabular}

Table 3. Distribution of patients according to histological diagnosis of breast lump

\begin{tabular}{lll}
\hline Histological diagnosis & Patients $(\mathrm{n}=163)$ & Percentage \\
Fibroadenoma & 102 & 62.6 \\
Fibrocystic disease & 27 & 16.6 \\
Benign phyllodes tumour & 6 & 3.6 \\
Juvenile papilloma & 6 & 3.6 \\
Chronic mastitis & 5 & 3.1 \\
Reactive dysplasia & 4 & 2.5 \\
Lipoma & 4 & 2.5 \\
Sebacious cyst & 4 & 2.5 \\
Leiomyoma & 2 & 1.2 \\
Ductal papilloma & 2 & 1.2 \\
Tubular adenoma & 1 & 0.6 \\
\hline
\end{tabular}

Table 4. Distribution of breast lesions according to age group

\begin{tabular}{|c|c|c|c|c|c|c|}
\hline Age(yrs) & $0-3$ & $4-7$ & $8-11$ & $12-$ & $15-$ & Total \\
\hline Lesion & & & & 15 & 18 & $(100 \%)$ \\
\hline Breast & $13(8.0 \%) 10$ & $0(6.1 \%)$ & $15(9$ & $2 \%) 45(27.6$ & $\%) 80$ & 163 \\
\hline lump & & & & & $(49.0 \%)$ & \\
\hline $\begin{array}{l}\text { Breast } \\
\text { abscess }\end{array}$ & $5(62.5 \%)-$ & - & & $1(12.5 \%)$ & $2(25.0 \%)$ & 8 \\
\hline $\begin{array}{l}\text { Puberty } \\
\text { mastitis }\end{array}$ & - & - & - & $5(71.4 \%)$ & $2(28.6 \%)$ & 7 \\
\hline $\begin{array}{l}\text { Mastitis } \\
\text { neonato- } \\
\text { rum }\end{array}$ & $6(100.0 \%)$ & & - & - & - & 6 \\
\hline $\begin{array}{l}\text { Gynaeco- } \\
\text { mastia }\end{array}$ & $1(20.0 \%)$ & & & $3(60.0 \%)$ & ) $1(20.0 \%)$ & 5 \\
\hline $\begin{array}{l}\text { Cavernous } \\
\text { haeman- } \\
\text { gioma }\end{array}$ & $1(50.0 \%)$ & $1(50.0$ & $\%)-$ & - & & 2 \\
\hline
\end{tabular}

\section{DISCUSSION}

Breast lesions are among the surgical problems seen in paediatric patients in our practice. These paediatric breast lesions present mostly as breast lumps. Other lesions of the breast seen were either diffuse enlargement or have features of inflammation indicating their infective nature. The breast lumps were mostly seen in the age range of 12 to 18 years which is the period of puberty development which indicates the possibility of the role of hormones in the development of 


\section{Clinicopathological profile of breast lesions and their management in paediatric patients seen in a tertiary health facility in Southern Nigeria

these lumps. The finding of fibroadenoma and fibroadenosis in the vast majority of the lumps is similar to the findings by other authors from other regions. [6, 7] We followed these patients up but not on a long term basis. However, a report of a case of recurrent fibroadenoma which ultimately transformed to a cysticercoma phyllodes and other reports of younger women developing breast cancer suggests that a long term follow up of these patients treated of breast fibroadenoma may be wise. [5, 8] The phyllodes tumours we saw in this study were treated with simple excision and there were no evidence of recurrence during the period of follow up. A similar study had reported only one case of recurrence in their series of eight cases corroborating the low incidence of recurrence with simple excision. [9] Inflammatory breast lesions and abscesses appeared to occur more in neonatal period and early infancy and were seen in both male and female patients. The reason for this neonatal occurrence is unclear. However some reports from other regions suggest that pressing the neonatal nipple to express the 'witch milk' in certain cultures may lead to it. This is not in our culture and we rather consider it as part of the features of neonatal sepsis commonly seen in our clime. We treated all cases of mastitis in neonates and infants medically, and deployed incision and drainage only when suppuration occurred. This is also the modality of treatment reported by other researchers. [10-12] The rest of the mastitis we encountered were mostly non infective occurring within the age range of 12 to 16 years which fitted into the age range reported for the highest incidence of puberty mastitis. They only needed reassurance and analgesics to resolve. The infective mastitis were treated with antibiotics, and if suppuration occurred, incision and drainage was carried out. Biopsy was taken in few cases where the features of inflammation were not clear, to rule out the inflammatory breast cancer which has been reported to be mistaken for mastitis. [13] The cases of gynaecomastia we encountered were mostly managed by counseling and reassurance to enable them overcome the embarrassment and psychosocial disorders which are recognized problems in that condition. [14-16] Subcutaneous mastectomy was performed only in one case of gynaecomastia secondary to intersex disorder. There was no case of ductal atresia in our series. This contrasts with report by McHoney et al in which ductal ectasia incidence was found to peak at about three years of age. [17] We put into consideration the small size or almost absent breast tissues (particularly in the neonates and younger children) in deciding the best modality of treatment. There have been controversies about whether to biopsy or not and what technique to use. The argument against biopsy is the risk of damaging normal breast tissues particularly due to the small amount of breast tissue at that age, and the possibility of not getting any additional information to guide treatment. This argument advocates more of the use of imaging in the diagnosis of these patients. [18] In our practice we withhold biopsy if clinical diagnostic features are strongly suggestive of mastitis neonatorum, gynaecomastia, haemangioma, and some cases of generally lumpy breast suggestive of fibroadenosis. On the other hand, in cases with obvious discreet breast lumps, biopsy was obtained by either trucut or open incisional or excisional technique. We preferred the open biopsy technique over the trucut biopsy in the paediatric patients as it tended to give us more reliable results. Additionally, the open technique achieves cure when it is excisional. We are concerned that Core needle biopsy, being a blind procedure, may stand a higher risk of missing the lesion and of damaging normal breast tissues in paediatric patients when compared with the adult counterparts because of the relatively smaller breast tissue. The suggestion by some authors to adopt watchful waiting, after imaging or histopathological examination of biopsies established that a breast lump was benign, does not consider the psychological burden the presence of such a lump places on the patient. $[19,20]$

It is reassuring that despite suggestions of a reduction in the age of incidence of breast cancer, there was no case in which malignancy was identified in our series.

This study has highlighted the fact that fibroadenoma and fibroadenosis are the commonest causes of breast lumps in female paediatric patients in our centre. They are mostly seen in their teenage years. There are no malignant breast lesions seen in our series. This is similar to the report by Cohen et al. [21] On the other hand, mastitis and abscess are the commonest breast lesions seen in neonates. Due to the peculiar nature of the breast and the lesions in children, we need to develop a standard protocol for diagnosis and treatment of breast lesions. A less aggressive and less invasive approach may be more suitable with more restraint on biopsies given the absence of breast malignancy in our series. This is in line with the recommendations by other researchers. [22-24] This approach has also been shown to be more cost effective. [25] However, a longer period of follow up may be more appropriate for patients who have had their fibroadenoma removed.

\section{CONCLUSION}

Breast lesions are not uncommon among paediatric patients in our centre. The majority of the lesions present as breast lump in the teenage years. Fibroadenoma and fibroadenosis are the commonest breast lesions and malignant lesions were not encountered. A less aggressive and less invasive approach may be more suitable with more restraint on biopsies in our patients. Longer periods of follow up in young girls who had biopsy for breast lump may be wise. Establishment of paediatric breast clinics may enhance a more focused and guided management of this group of patients.

\section{REFERENCES}

[1] Odle TG. Radiol Technol Breast disease in children and adolescents. 2015;86(3):301-324.

[2] Cayci C, Simmons P, Petty P, Lemaine V. Gynecomastia in Adolescent Males. Seminars in Plastic Surgery. 2013;27(01):056-061. Available from: https://dx.doi.org/10. 1055/s-0033-1347166.

[3] Omar L, Gleason MK, Pfeifer CM, Sharma P, Kwon JK. Management of Palpable Pediatric Breast Masses With Ul- 
trasound Characteristics of Fibroadenoma: A More Conservative Approach. American Journal of Roentgenology. 2019;212(2):450-455. Available from: https://dx.doi.org/10. 2214/ajr.17.19482.

[4] Schaffar R, Bouchardy C, Chappuis PO, Bodmer A, Benhamou S, Rapiti E. A population-based cohort of young women diagnosed with breast cancer in Geneva, Switzerland. PLOS ONE. 2019;14(9):e0222136-e0222136. Available from: https://dx.doi.org/10.1371/journal.pone.0222136.

[5] Keyzer-Dekker CMG, de Vries J, Mertens MC, Roukema JA, van der Steeg AFW. The impact of diagnosis and trait anxiety on psychological distress in women with early stage breast cancer: A prospective study. British Journal of Health Psychology. 2014;19(4):783-794. Available from: https://dx. doi.org/10.1111/bjhp.12076.

[6] STAUFFER WM, KAMAT D. Neonatal mastitis. Pediatric Emergency Care. 2003;19(3):165-166. Available from: https: //dx.doi.org/10.1097/01.pec.0000081239.98249.09.

[7] Durmaz E, Oztek MA, Habibi HA, Kesimal U, Sindel HT. Breast diseases in children: the spectrum of radiologic findings in a cohort study. Diagnostic and Interventional Radiology. 2017;23(6):407-413. Available from: https://dx.doi.org/10.5152/dir.2017.17033.

[8] Cohen O, Avinadav E, Sharon E, Pirogovsky A, Freud E. Pediatric and Adolescent Surgical Breast Clinic: Preliminary Experience. Journal of Pediatric and Adolescent Gynecology. 2020;33(1):23-26. Available from: https://dx.doi.org/ 10.1016/j.jpag.2019.08.010.

[9] McLaughlin CM, Gonzalez-Hernandez J, Bennett M, Piper HG. Pediatric breast masses: an argument for observation. Journal of Surgical Research. 2018;228:247-252. Available from: https://dx.doi.org/10.1016/j.jss.2018.03.056.

[10] Wang C, Yu N, Zhu L, Zeng A;.

[11] Efrat M, Mogilner JG, Iujtman M, Eldemberg D, Kunin J, Eldar S. Neonatal mastitis-diagnosis and treatment. Isr J Med Sci. 1995;31(9):558-60.

[12] Mchoney M, Munro F, Mackinlay G;

[13] Hafeez S, Balarezo F, Ricci A;

[14] Richards MK, Goldin AB, Beierle EA, Doski JJ, Goldfarb M, Langer M, et al. Breast Malignancies in Children: Presentation, Management, and Survival. Annals of Surgical Oncology. 2017;24(6):1482-1491. Available from: https://dx.doi.org/10.1245/s10434-016-5747-5.

[15] Gunden JR, Bendahhou K, Benider A, Khalil AI, Khalis M, Wilson ML, et al. Evaluating the incidence of inflammatory breast cancer using population- and hospital-based cancer registries in Casablanca, Morocco. Breast Disease. 2019;38(2):39-45. Available from: https://dx.doi.org/10. $3233 /$ bd- 180357 .

[16] Westfal ML, Perez NP, Hung YC, Chang DC, Kelleher CM. Pathologic discordance to clinical management decisions suggests overtreatment in pediatric benign breast disease. Breast Cancer Research and Treatment. 2019;176(1):101108. Available from: https://dx.doi.org/10.1007/s10549019-05224-w.

[17] Scolnik D, Ruwaili NA. Neonatal mastitis: Controversies in management. Journal of Clinical Neonatology. 2012;1(4):207-207. Available from: https://dx.doi.org/10. 4103/2249-4847.105997.

[18] and SK. Clinical Evaluation of Breast in Childhood. European Journal of Breast Healt. 2019;15(3):137-140. Available from: https://dx.doi.org/10.5152/ejbh.2019.4745.

[19] Ismail S, Alaidi S, Jouni S, Kassab Y, Al-Shehabi Z. Recurrent giant fibroadenomas with transformation to cystosarcoma phyllodes in a 17-year-old girl: a rare case report from Syria. Journal of Medical Case Reports. 2019;13(1):378-
378. Available from: https://dx.doi.org/10.1186/s13256019-2313-3.

[20] Shahriari M, Ghasemi K, Bordbar M, Shakibazad N. Gynecomastia as a late complication of childhood cancer and its treatment that can affect the quality of life of male survivors. Seminars in Oncology. 2019;46(2):155-159. Available from: https://dx.doi.org/10.1053/j.seminoncol.2019.04.003.

[21] Manjiri S, Padmalatha SK, Jeevak S. A Prospective Observational Study of Breast Lumps in Adolescent Girls: Tertiary Care South Indian Teaching Hospital Experience. Indian Journal of Surgical Oncology. 2018;9(3):402-406. Available from: https://dx.doi.org/10.1007/s13193-018-0773-3.

[22] Lee EJ, Chang YW, Oh JH, Hwang J, Hong SS, Kim HJ. Breast Lesions in Children and Adolescents: Diagnosis and Management. Korean J Radiol. 2018;(5):978-991.

[23] Englert EG, Ares G, Henricks A, Rychlik K, Hunter CJ. Analysis of factors predicting surgical intervention and associated costs in pediatric breast masses: a single center study. Pediatric Surgery International. 2018;34(6):679-685. Available from: https://dx.doi.org/10.1007/s00383-018-4268-7.

[24] Valeur NS, Rahbar H, Chapman T;

[25] Sancho-Garnier H, Colonna M. Breast cancer epidemiology. Presse Med. 2019;48(10):1076-1084.

\section{AUTHOR BIOGRAPHY}

Okoro Philemon E Departments of Surgery, and Anatomic Pathology, University of Port Harcourt Teaching Hospital, Port Harcourt, Nigeria

Obiora Christopher Departments of Surgery, and Anatomic Pathology, University of Port Harcourt Teaching Hospital, Port Harcourt, Nigeria 